Article

\title{
Evaluation of Normalized Difference Water Index as a Tool for Monitoring Pasture Seasonal and Inter-Annual Variability in a Mediterranean Agro-Silvo-Pastoral System
}

\author{
João Serrano ${ }^{1, *(\mathbb{D})}$, Shakib Shahidian ${ }^{1}$ and José Marques da Silva ${ }^{1,2}$ (D) \\ 1 Instituto de Ciências Agrárias e Ambientais Mediterrânicas, Departamento de Engenharia Rural, \\ Universidade de Évora, P.O. Box 94, 7002-554 Évora, Portugal; shakib@uevora.pt (S.S.); \\ jmsilva@uevora.pt (J.M.d.S.) \\ 2 Agroinsider Lda. (Spin-off of Universidade de Évora), Parque Industrial e Tecnológico de Évora, \\ R. Circular Norte, NERE, Sala 18, 7005-841 Évora, Portugal \\ * Correspondence: jmrs@uevora.pt; Tel.: +351-963-824-046
}

Received: 31 October 2018; Accepted: 25 December 2018; Published: 1 January 2019

\begin{abstract}
Extensive animal production in Iberian Peninsula is based on pastures, integrated within the important agro-silvo-pastoral system, named "montado" in Portugal and "dehesa" in Spain. Temperature and precipitation are the main driving climatic factors affecting agricultural productivity and, in dryland pastures, the hydrological cycle of soil, identified by soil moisture content (SMC), is the main engine of the vegetation development. The objective of this work was to evaluate the normalized difference water index (NDWI) based on Sentinel-2 imagery as a tool for monitoring pasture seasonal dynamics and inter-annual variability in a Mediterranean agro-silvo-pastoral system. Forty-one valid NDWI records were used between January and June 2016 and between January 2017 and June 2018. The 2.3 ha experimental field is located within the "Mitra" farm, in the South of Portugal. Soil moisture content, pasture moisture content $(\mathrm{PMC})$, pasture surface temperature $\left(\mathrm{T}_{\mathrm{ir}}\right)$, pasture biomass productivity and pasture quality degradation index (PQDI) were evaluated in 12 satellite pixels $(10 \mathrm{~m} \times 10 \mathrm{~m})$. The results show significant correlations $(p<0.01)$ between NDWI and: (i) SMC $\left(R^{2}=0.7548\right)$; (ii) PMC $\left(R^{2}=0.8938\right)$; (iii) $\mathrm{T}_{\text {ir }}\left(\mathrm{R}^{2}=0.5428\right)$; (iv) biomass $\left(\mathrm{R}^{2}=0.7556\right)$; and (v) PQDI $\left(R^{2}=0.7333\right)$. These findings suggest that satellite-derived NDWI can be used in site-specific management of "montado" ecosystem to support farmers' decision making.
\end{abstract}

Keywords: Sentinel-2; soil moisture content; pasture moisture content; decision making

\section{Introduction}

Extensive animal production in Portugal, especially of cows and sheep, is based on pastures integrated within the context of "montado", an agro-silvo-pastoral system, mainly under a sparse canopy of holm oak (Quercus ilex ssp. rotundifolia Lam.) [1]. The tree cover is mostly a result of natural regeneration and the evergreen canopy can shade $25 \%$ to $100 \%$ of the land. The trees can be valuable as fodder crop, providing acorns and leafy branches in autumn and winter, when the herbage production is low. The understory consists of evergreen shrubs and a ground layer covered by annual herbaceous species that dry and die off at the end of spring [2]. Permanent pastures constitute the herbaceous layer, a major source of feed for livestock, and are of major importance from an ecological point of view and as a carbon sink [3]. These are pastures with low productivity growing on poor and marginal soils, involving little use of fertilizers, and thus only capable of sustaining low animal allotments, resulting in very small economic returns for the farmers [4]. However, there is a growing pressure to feed the 
world population, especially in terms of animal protein, as a result of the exponential demographic growth in some parts of the globe. Thus, the "montado" system, like many other production systems, needs to evolve towards intensification, incorporating more and more inputs, namely fertilizers, water, seeds of diverse species, and mainly, technology to help decision making.

The Mediterranean climate is characterized by a strong seasonal variability, consisting of cold winters, very hot and dry summers and significant inter-annual irregularity in the distribution of rainfall during autumn, winter and spring [4]. These characteristics strongly influence the growth pattern of dryland pastures, and thus, are an additional challenge for the management of animal grazing. The number of animals at feed lots, the rotation of the animals between lots or feed supplementation are dynamic decisions that depend on the evolution of the pasture in terms of productivity, and especially quality. Another important aspect in this context is related to the application of fertilizers or amendments, as part of a strategy to improve and correct the limitations imposed by an acid substrate (soil) in the Southern region of Portugal and its reduced fertility. The common practice in the permanent dryland pastures in this region is the infrequent application of phosphate fertilizers as top dressing [4]. Nonetheless, this application is not always justified, since in dry years, the fertilizer is hardly made available to the plants, and can thus be a waste of resources. On the other hand, in years with a regular distribution of rainfall, the application timing is of high importance. If plants do not have good vegetative vigor (leaves with high chlorophyll and moisture content), it will be very difficult for the nutrients provided in the fertilizer to carry out their role in the plants physiological processes. Thus, it is fundamental to monitor the state of the soil in term of moisture content, and the condition of the plants, in terms of vegetative vigor (by measuring the chlorophyll content or leaf water content) and evaluate the potential to produce biomass through the photosynthetic process.

The knowledge of soil moisture plays a determinant role in several hydrological and atmospheric processes and is crucial in the water cycle and energy exchange of the Earth's surface. In fact, soil moisture content (SMC) controls the exchange of latent and sensible heat between land and atmosphere across the surface, which is the trigger of feedback mechanisms in land-atmosphere interactions [5]. Soil moisture has great importance in various applications such as natural risk assessment, hydrology, climatology, ecology, and agronomy, whereby the retrieval of spatial distribution of SMC on a large scale is an important research topic [6].

The measurement of soil moisture at a given depth is a lengthy and demanding process. For the purpose of scientific study some proximal sensors have been developed that quickly characterize the soil moisture content using time domain reflectometry (TDR) probes that measure SMC in pre-installed access tubes in the soil. These measurements are, nonetheless, discreet, and may not portray the spatial pattern of soil moisture, especially in undulated fields typical of this region. Another possibility for estimating soil moisture is based on the use of soil apparent electrical conductivity sensors, which have a strong correlation with SMC [7]. Despite their usefulness in mapping the evolution of the spatial patterns of soils moisture, they require frequent surveys of the field.

Temperature at the plant surface is another relevant parameter for the development of physiological processes. For example, a significant decrease in the environmental temperature during winter triggers a period of vegetative dormancy. On the other hand, high temperatures during summer lead to a decrease in the soil moisture content, and soil moisture deficits can often lead to drought-induced vegetation stress which gradually cause drying and death of the annual plants [8]. Accurately monitoring and assessing near-real time vegetation drought may provide decision makers accurate, synoptic, and timely information for effective drought planning and mitigation and should reduce economic losses [8].

The use of infrared thermal cameras provides a process of monitoring the plant surface temperatures, revealing situations of water stress. Nonetheless it is a point-discreet process that cannot be applied to the whole field. 
On the other hand, measuring productivity and pasture quality requires cutting and laboratory processing of representative samples, which cannot be carried out by farmers for large and heterogeneous plots. Various published works have focused on the "Grassmaster II" probe [9], which provides very acceptable estimates of pasture productivity, although has the main limitation of requiring an on site survey and measurement of discreet points. The active optical sensors (OAS), such as "OptRx", can be mounted on mobile platforms and associated with a GNSS (global navigation satellite systems), antenna [10], and used to measure NDVI (normalized difference vegetation index; Equation (1), which is the normalized difference between the near infrared (NIR) and visible red reflectance, corresponding respectively to the strong chlorophyll absorption region and high reflectance plateau of vegetation canopies [6]. This index is responsive to changes in both the chlorophyll content and the intracellular spaces in the spongy mesophyll of plant leaves. The anatomy and physiology of the leaf absorbs radiation from wavelengths around the red area of the spectrum and reflects the near infrared [3]. Higher NDVI values reflect greater vigor and photosynthetic capacity (or greenness) of vegetation canopy, whereas lower NDVI values are reflective of vegetative stress resulting in chlorophyll reductions and changes in the leaves' internal structure due to wilting [3-8]. The two aforementioned channels used in NDVI can sense through different depths of vegetation canopies: near infrared channel can "see" through roughly eight leaf layers, while the red channel sees only one leaf layer or less because of the strong chlorophyll absorption [11].

$$
\mathrm{NDVI}=\frac{\mathrm{NIR}-\mathrm{RED}}{\mathrm{NIR}+\mathrm{RED}}
$$

where NIR—Near infrared; RED—red.

These OAS provide a very interesting response in terms of crude protein $(\mathrm{CP})$, neutral detergent fiber (NDF) and pasture quality degradation index (PQDI) estimates [10], although they require the presence of a technician and running a mobile platform in repeated swats to adequately cover the field in order to obtain representative maps of the spatial variability of the parameters being measured.

As an alternative to this set of proximal sensors, satellite imagery (such as Sentinel-2), provided with very interesting temporal and spatial resolutions, is currently being studied by many research teams for very promising applications related to agriculture. Vegetation indexes, resulting from empirical combinations of reflectance in various wavelengths, have proved very useful for detecting changes in biomass status as measured by changes in chlorophyll activity (biomass vegetation indexes, $\mathrm{BVI}$ ) and vegetation water content (moisture vegetation indexes, MVI) [2]. Indexes obtained by remote sensing have, in comparison to proximal sensors, important advantages in terms of the scale of the response, speed of processing, and low cost [12]. The major disadvantage of optical satellite imagery is the dependence on a clear, cloud-free view of the object of interest, which is especially challenging in temperate and rainy regions [13], leading to studies on complementing remote sensing by satellite, with proximal sensing, specially in the Mediterranean-type "montado" ecosystem, where the tree canopy obstructs the access to the pasture under the trees.

As already mentioned, NDVI is an index primarily related to canopy chlorophyll content [14] and one of the most widely used indexes for the remote sensing of vegetation $[3,11]$. Nonetheless, the main engine for the development of the dryland pastures is the hydrological cycle of the soil, and thus the temporal tracking of vegetation mass with spectral measures has been widely investigated, especially in water-limited regions [2], which is the case of the Mediterranean region. The accurate assessment of the seasonal dynamic of drought in these regions by the use of remote-sensing and field observations is essential to determination of the major constraints of such ecosystems [2].

The normalized difference water index (NDWI, Equation (2); [11]) is an index which can be obtained from band 8A (B8A; $865 \mathrm{~nm})$ and band 11 (B11; $1610 \mathrm{~nm})$ of Sentinel-2 spectral data and which can be of great interest as a support to decision making in terms of pasture and grazing management. It was initially proposed for describing the status of the vegetation water content over large areas from space: the NDWI values over areas with dead grass are negative, while those over green vegetation are 
positive [11]. The NDWI is a measure of liquid water molecules in vegetation canopies that interact with the incoming solar radiation [11], specially conceived for the estimate of soil moisture and canopy water content $[5,14]$. The NDWI is often a function of local climate and soil properties controlling water availability [5], and sensitive to changes in liquid water because it incorporates a short-wave infrared (SWIR) band (B8A; Equation (2)). This green vegetation spectra region is dominated by water absorption effects that capture important information on seasonally variable water status $[5,15]$. The NDWI responds to changes in both the water content (absorption of B8A radiation) and spongy mesophyll (reflectance of B11 radiation) in vegetation canopies, respectively [11].

$$
\mathrm{NDWI}=\frac{\mathrm{B} 8 \mathrm{~A}-\mathrm{B} 11}{\mathrm{~B} 8 \mathrm{~A}+\mathrm{B} 11}
$$

The objective of this work was to evaluate NDWI based on Sentinel-2 imagery as a tool for monitoring pasture seasonal dynamics and inter-annual variability in a Mediterranean agro-silvo-pastoral system.

\section{Materials and Methods}

Figure 1 shows the chronological diagram of data acquisition of this experimental study.

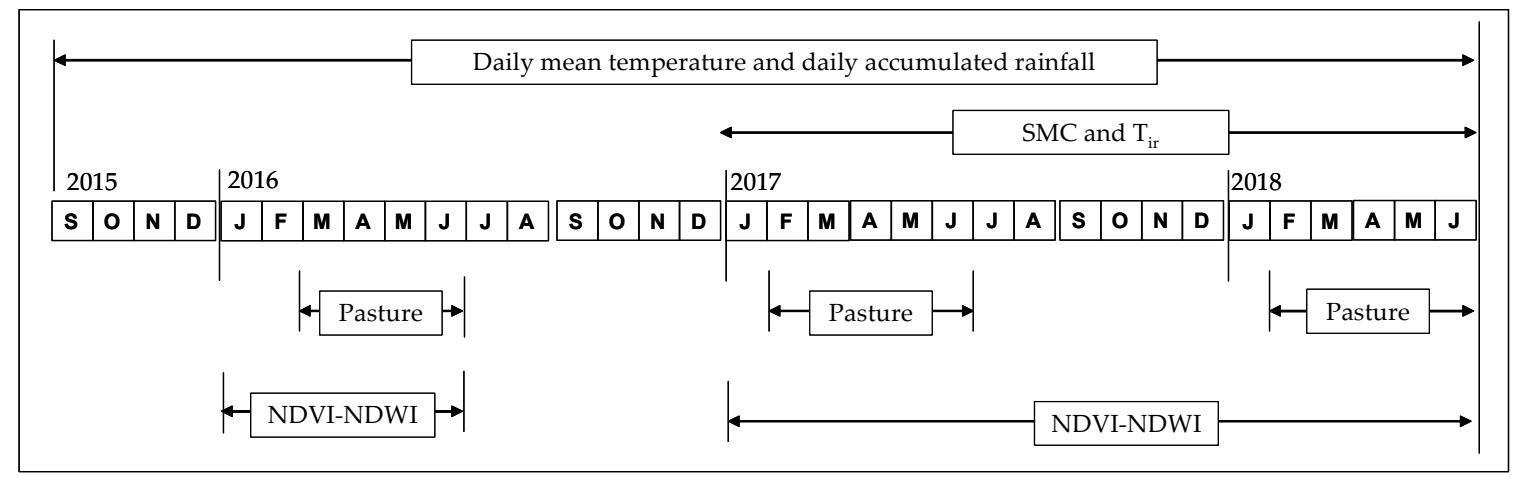

Figure 1. Chronological diagram of data acquisition of daily mean temperature, daily accumulated rainfall, soil moisture content $(\mathrm{SMC})$, pasture surface temperature $\left(\mathrm{T}_{\mathrm{ir}}\right)$, pasture productivity and quality, normalized difference vegetation index (NDVI) and normalized difference water index (NDWI) Sentinel-2 satellite-based.

\subsection{Study Area}

The area of the study, a paddock, with 2.3 ha (Figure 2), is located in the south of Portugal (coordinates $38^{\circ} 32.2^{\prime} \mathrm{N} ; 8^{\circ} 01.1^{\prime} \mathrm{W}$ ). A field of Quercus ilex ssp. rotundifolia Lam., with a tree density of approximately 10 trees $\mathrm{ha}^{-1}$, was cultivated for more than 30 years with bio-diverse permanent pastures (grasses, legumes and others) and used for sheep grazing. The dominating soil type is Cambisol with a granite origin [16]. The average characteristics of the soil in the top layer (0-0.20 $\mathrm{m}$ depth) are: sandy loam texture (mean clay content $=9.7 \pm 2.7 \%$; mean silt content $=9.7 \pm 2.5 \%$; mean sand content $=80.6 \pm 2.4 \%$ ); acid (mean pH was $5.4 \pm 0.3$ ); rich in potassium $\left(\right.$ mean $\left.=269.9 \pm 135.9 \mathrm{mg} \cdot \mathrm{kg}^{-1}\right)$; average level of organic matter $(\mathrm{mean}=2.4 \pm 0.8 \%)$, magnesium $\left(\right.$ mean $=95.6 \pm 43.7 \mathrm{mg} \cdot \mathrm{kg}^{-1}$ ) and phosphorus $\left(\right.$ mean $\left.=92.6 \pm 62.4 \mathrm{mg} \cdot \mathrm{kg}^{-1}\right)$; poor in nitrogen (mean $=0.1 \pm 0.0 \%$ ) [17].

The relief of the field is slightly wavy, with altimetry between 215 and $219 \mathrm{~m}$, which is representative of the typical pattern in the region. 


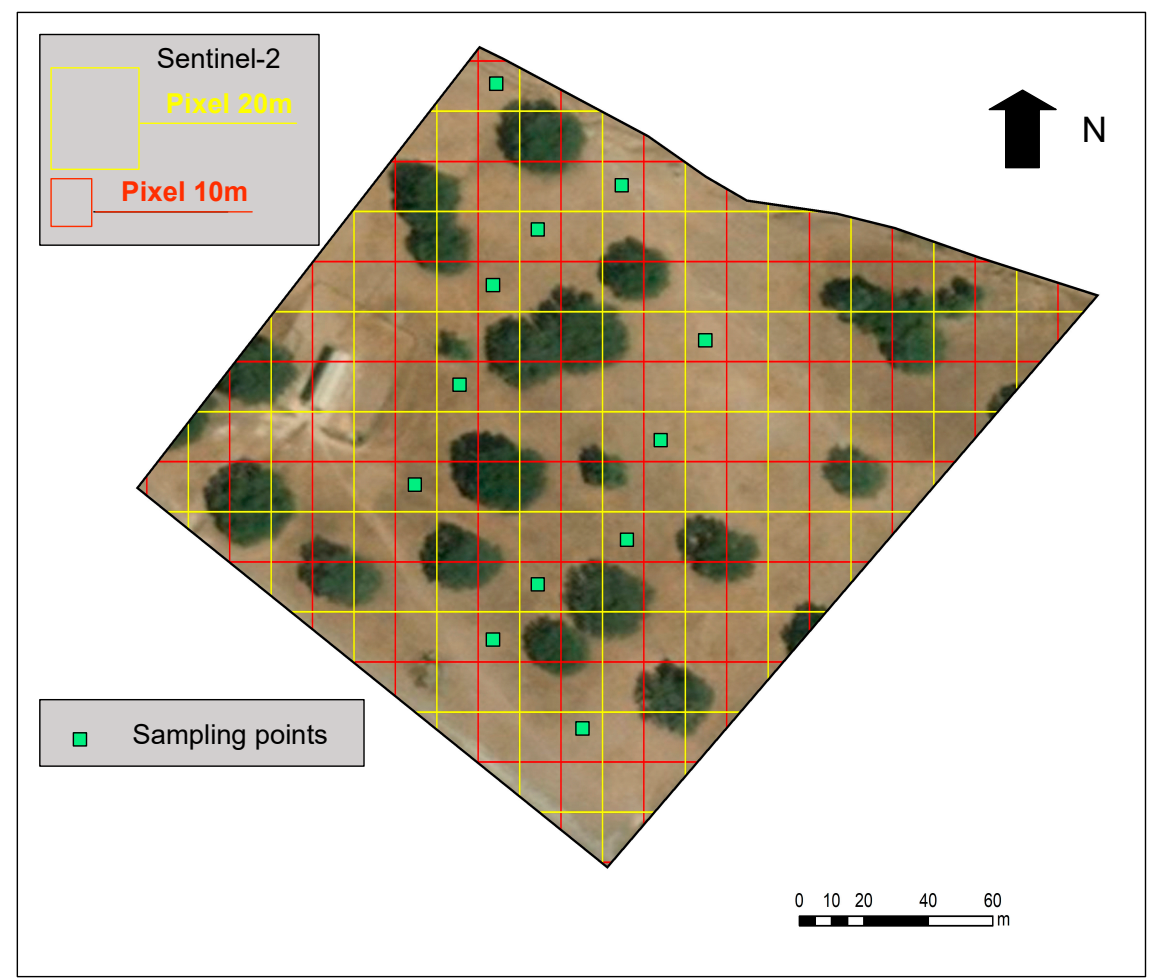

Figure 2. The experimental field showing the sampling points and Sentinel-2 pixel grid (10 and $20 \mathrm{~m})$.

\subsection{Climate}

The Mediterranean climate is characterized by dry summers, with less than $10 \mathrm{~mm}$ average monthly rainfall, and mild or moderately cold winters, with an unpredictable rainfall regime. The monthly average temperature range is $8{ }^{\circ} \mathrm{C}$ to $26^{\circ} \mathrm{C}$ and the minimum temperatures are close to $0{ }^{\circ} \mathrm{C}$ in the winter time and maximum temperatures are close to $40{ }^{\circ} \mathrm{C}$ in the summer. The annual rainfall range is 400 to $600 \mathrm{~mm}$ and it mainly takes place between October and March.

The experiment was carried out between September 2015 and June 2018. Figure 3 shows the corresponding daily thermo-pluviometric diagram of the "Mitra" meteorological station. This period covers the complete seasonal cycle, and therefore, a wide variety of climate and soil water content situations taking into account the marked irregularity of inter-annual distribution of the rainfall in this region.

The accumulated rainfall between September and June was $544.1 \mathrm{~mm}$ in 2015-2016, $412.3 \mathrm{~mm}$ in 2016-2017 and $610 \mathrm{~mm}$ in 2017-2018. Particularly in the months between February and June, the accumulated rainfall was $327 \mathrm{~mm}$ in 2016, $167 \mathrm{~mm}$ in 2017 and $461 \mathrm{~mm}$ in 2018, which allow us to classify these three springs as average, dry and wet, respectively. From the end of June onwards, a significant drop in the rainfall and the higher temperatures naturally lead to the end of the pasture's productive cycle, which only resumes the following autumn.

\subsection{Pasture and Soil Monitoring}

Figure 2 shows the 12 sampling points of SMC and pasture parameters. Each point represents a $10 \mathrm{~m} \times 10 \mathrm{~m}$ pixel area of Sentinel-2 imagery.

\subsubsection{Measurements of Soil Moisture Content (SMC) and Pasture Surface Temperature $\left(\mathrm{T}_{\mathrm{ir}}\right)$}

In December 2016, 12 PVC tubes were installed in the ground to a depth of $0.20 \mathrm{~m}$. Soil moisture content measured at $0.20 \mathrm{~m}$ depth is regarded as a proxy of the water availability for the plant photosynthetic activity due to their shallow root depth [5]. 


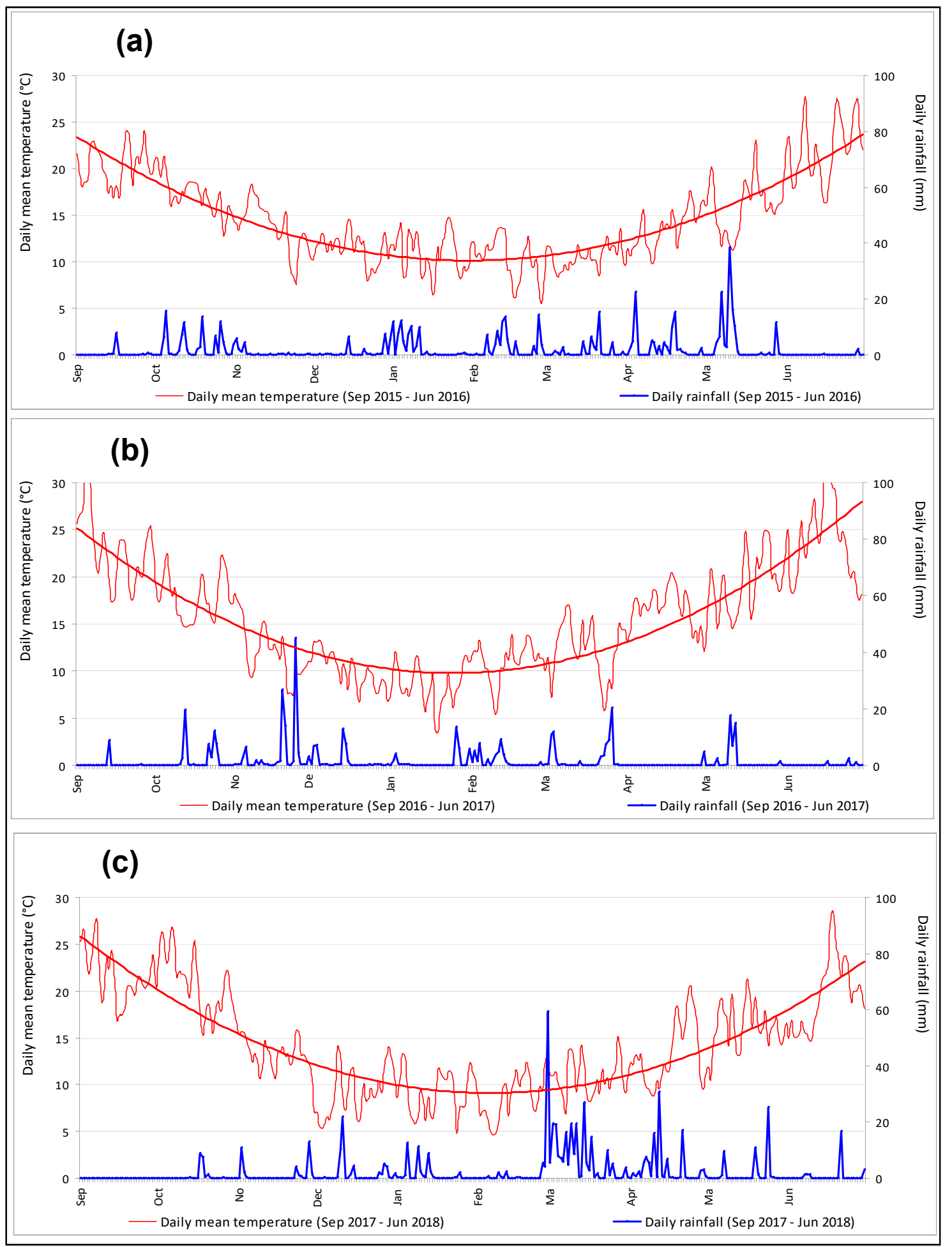

Figure 3. Thermo-pluviometric diagrams of the "Mitra" meteorological station: (a) September 2015-June 2016; (b) September 2016-June 2017; (c) September 2017-June 2018.

These access tubes permit monitoring of SMC profiles using portable time domain reflectometry (TDR) probes (TRIME-FM, IMKO-Micromodultechnik, GmbH, Ettlingen, Germany). Between January 2017 and June 2018 measurements were carried out monthly, always at same time (9 a.m.) at a depth of $0-0.2 \mathrm{~m}$. 
Pasture surface temperature measurements were carried out in each sampling point monthly, always at same time (9 a.m.), between January 2017 and June 2018. An infrared camera (ThermaCAM ${ }^{\mathrm{TM}}$ FLIR Systems, Wilsonville, OR, USA) was used. Thermography images were analyzed using ResearchIR ${ }^{\circledR} 3.0$ (FLIR Systems, Wilsonville, OR, USA) software. Processed data from the infrared images were exported to a spreadsheet for calculation of the mean and standard deviation of pasture surface temperature.

\subsubsection{Pasture Sample Collection and Analysis}

A composite pasture sample was collected at three representative locations (each with $0.25 \mathrm{~m}^{2}$ area) within each selected $10 \mathrm{~m} \times 10 \mathrm{~m}$ pixel of Sentinel-2 imagery. Collection was carried out on each monitoring date of 2016, 2017 and 2018 (coinciding with the dates of the satellite imagery without cloud cover): at the end of winter (February and March), and then each month during spring (April, May and June). In total, 168 pasture samples were collected (48 in 2016, 60 in 2017 and 60 in 2018).

At each sampling point, pasture was cut at 1 to $2 \mathrm{~cm}$ above ground level and collected. It was then (i) weighted immediately to obtain fresh mass; (ii) dehydrated $\left(72 \mathrm{~h}\right.$ at $\left.65^{\circ} \mathrm{C}\right)$; and (iii) weighted again, in order to obtain pasture biomass production $\left(\mathrm{kg} \cdot \mathrm{ha}^{-1}\right)$ and pasture moisture content (PMC, $\%$ ). The dehydrated samples were analysed (both in \% of dry matter) in order to determine the content of CP and NDF [18]. Based on these values, the PQDI, ratio between NDF and CP, was calculated.

\subsubsection{Vegetation Multispectral Measurements by Remote Sensing}

Sentinel-2 optical images (freely available from the European Space Agency, ESA), were used. For this work, Sentinel-2 band 4 (B4; $10 \mathrm{~m}$ spatial resolution; $665 \mathrm{~nm}$ ), band 8 (B8; $10 \mathrm{~m}$ spatial resolution; $842 \mathrm{~nm}$ ), band $8 \mathrm{~A}$ (B8A; $20 \mathrm{~m}$ spatial resolution; $865 \mathrm{~nm}$ ) and band 11 (B11; $20 \mathrm{~m}$ spatial resolution; $1610 \mathrm{~nm}$ ), atmospherically corrected imagery, were extracted from Copernicus data hub and used to calculate NDVI (Equation (1)) and NDWI (Equation (2)). This data was obtained for the 12 geo-referenced pixels where the measurements of SMC and $\mathrm{T}_{\text {ir }}$ were carried out and pasture samples were collected. In order to make the reconstruction of historical NDVI and NDWI trends, time series NDVI and NDWI records were retrieved between January and June 2016 and between January 2017 and June 2018. A preliminary processing was carried out on these records to remove outliers due to the presence of clouds. Only the images without presence of clouds were used in the analysis.

\subsection{Statistical Analysis of the Data}

The mean and standard deviation were calculated for all parameters (biomass, PMC, CP, NDF, PQDI, SMC, $T_{\text {ir }}$, NDVI and NDWI) data.

Regression analysis $(p<0.05)$ was performed between (i) NDWI and NDVI (for all valid records between January and June 2016 and between January 2017 and June 2018; Figure 1); (ii) NDWI, SMC and $\mathrm{T}_{\text {ir }}$ (for all monthly sampling date, between January 2017 and June 2018; Figure 1); (iii) NDWI and pasture parameters (biomass, PMC and PQDI; for all monthly sampling date between February or March and June 2016-2018; Figure 1), using the proportion of explained variance as estimated by the coefficient of determination $\left(\mathrm{R}^{2}\right)$, using 'MSTAT-C' software.

\section{Results and Discussion}

\subsection{Evolution of Soil Moisture Content (SMC) and Pasture Surface Temperature $\left(T_{i r}\right)$}

Table 1 shows the evolution of the mean SMC and $\mathrm{T}_{\text {ir }}$ of the "Mitra" experimental field between January 2017 and June 2018. Between January and June 2017, as the seasons succeeded one another (winter: January-March; and spring: April-June), there was a tendency for a decrease in SMC and an increase in $T_{i r}$, which reflects the natural effect of climate conditions, specially the air temperature/ rainfall pair (see Figure 3). 
Table 1. Descriptive statistics (mean \pm standard deviation) of soil moisture content (SMC) and pasture surface temperature $\left(\mathrm{T}_{\mathrm{ir}}\right)$ measured at the 12 sampling points of the studied field, for each sampling date, between January 2017 and June 2018.

\begin{tabular}{cccc}
\hline Parameters & DOY & SMC (\%) & $\mathbf{T}_{\text {ir }}\left({ }^{\circ} \mathbf{C}\right)$ \\
\hline 2017 & & & \\
January & 15 & $18.3 \pm 3.3$ & $3.8 \pm 2.5$ \\
February & 50 & $20.1 \pm 3.2$ & $12.2 \pm 1.0$ \\
March & 80 & $15.1 \pm 2.5$ & $12.2 \pm 0.8$ \\
April & 110 & $10.1 \pm 2.1$ & $23.5 \pm 2.9$ \\
May & 140 & $9.4 \pm 2.0$ & $35.8 \pm 2.3$ \\
June & 165 & $8.9 \pm 1.9$ & $33.0 \pm 5.6$ \\
July & 195 & $7.4 \pm 2.0$ & $32.1 \pm 3.1$ \\
August & 215 & $7.2 \pm 1.9$ & $31.0 \pm 4.2$ \\
September & 255 & $7.0 \pm 2.6$ & $22.3 \pm 4.7$ \\
October & 290 & $10.4 \pm 1.9$ & $20.5 \pm 0.9$ \\
November & 330 & $12.3 \pm 2.0$ & $9.1 \pm 0.3$ \\
December & 345 & $18.8 \pm 2.7$ & $5.9 \pm 2.2$ \\
\hline 2018 & & & \\
January & 15 & $21.9 \pm 3.6$ & $1.9 \pm 1.2$ \\
February & 40 & $17.8 \pm 2.8$ & $0.5 \pm 1.8$ \\
March & 50 & $23.9 \pm 4.6$ & $12.5 \pm 2.0$ \\
April & 100 & $23.6 \pm 3.8$ & $12.7 \pm 1.9$ \\
May & 125 & $18.8 \pm 2.6$ & $12.9 \pm 1.0$ \\
June & 150 & $13.5 \pm 2.2$ & $16.7 \pm 0.8$ \\
\hline
\end{tabular}

DOY - day of the year; SMC—-soil moisture content; $\mathrm{T}_{\text {ir }}$-pasture surface temperature.

Soil moisture is a critical component in land surface-atmospheric processes, and prolonged soil moisture deficits often lead to drought induced vegetation stress [8]. Pasture surface temperature retrieved from thermal infrared $\left(\mathrm{T}_{\mathrm{ir}}\right)$ provides information about temperature extremes encountered during crop development in this region: extremely low in winter and extremely high in summer, and the consequences on stress and stomatal opening/closure process [19]. In the summer period, especially in the months of July and August, $\mathrm{T}_{\mathrm{ir}}$ reaches maximum values, while soil moisture has an opposite behaviour. After the arrival of autumn and during winter there is a gradual decrease in $\mathrm{T}_{\mathrm{ir}}$ and an increase in SMC. Nonetheless, in spring of 2018, the concentration of rainfall during the months of March, April and May (see Figure 3) delayed the normal decrease in SMC and even induced an irregular behaviour of $\mathrm{T}_{\mathrm{ir}}$. The combination of these conditions (namely the persistence of relatively high SMC values and the less drastic raise in $\mathrm{T}_{\text {ir }}$ ) impacts the evolution of the growth cycle of dryland pastures, both in terms of productivity, and quantity [4]. According to Wessels et al. [20], SMC is the main factor determining the composition, distribution and growth status of vegetation in arid and semi-arid regions. The temporal variability of SMC is a relevant factor, namely in the management of irrigation in intensive production systems (irrigated pastures and forages) and in the choice of the best opportunity for fertilizer topdressing, since it requires soil moisture in order to have a real impact on the pasture.

Figure 4 shows a negative significant correlation between SMC and $\mathrm{T}_{\mathrm{ir}}\left(\mathrm{R}^{2}=0.6656 ; p<0.01\right)$ over sampling times (between January 2017 and June 2018).

The combined effect of air temperature and rainfall distribution has an inverse effect on SMC and $\mathrm{T}_{\mathrm{ir}}$; the two factors that control the vegetative development: a gradual decrease in rainfall and a gradual increase in air temperature tend to decrease SMC and increase $T_{i r}$, and vice versa. For example, since photosynthesis of plants from temperate regions is optimized at $20-25{ }^{\circ} \mathrm{C}$ [21], it is possible to identify three physiological periods in the Mediterranean region: (i) winter period, in which transpiration is minimum and the stomata open only to allow gas exchange; (ii) the spring and autumn period, in which the soil moisture is sufficient for plants to control the leaf temperature through 
transpiration; and (iii) the summer period, in which soil moisture is insufficient for control of the leaf temperature by the plants, leading to senescence and crop maturity.

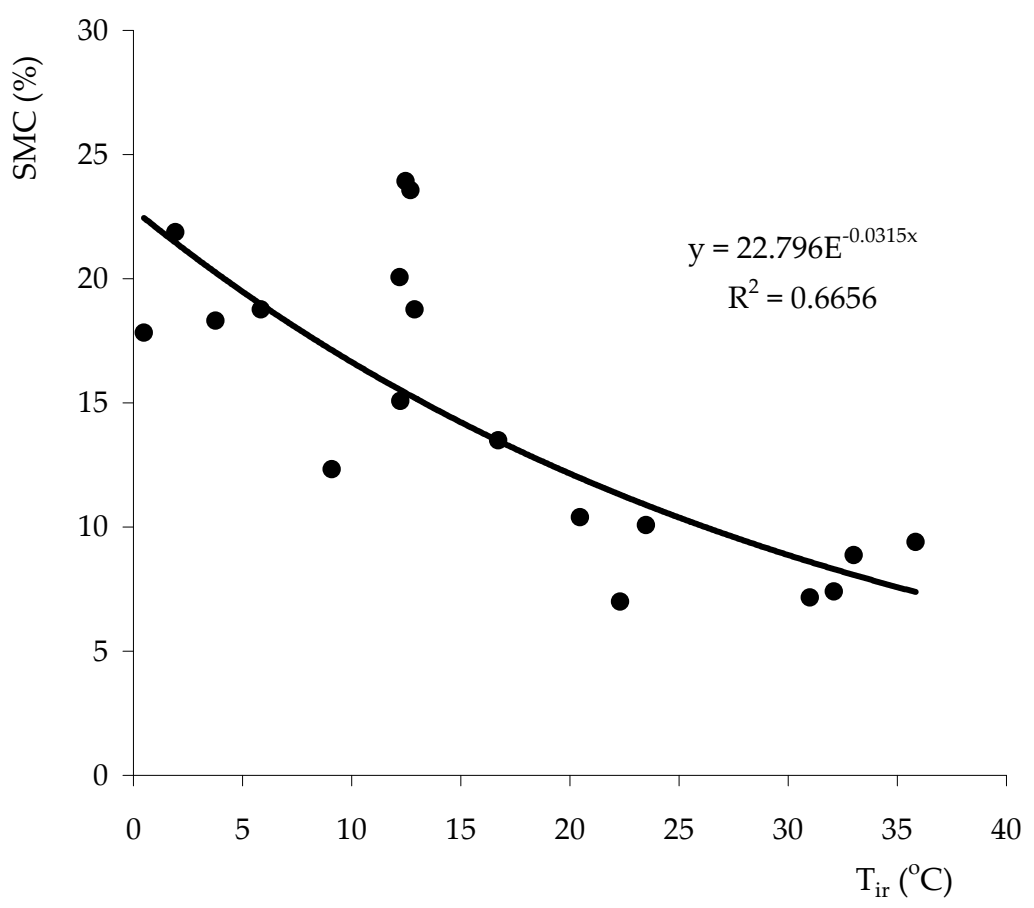

Figure 4. Relationship between pasture surface temperature $\left(\mathrm{T}_{\mathrm{ir}}\right)$ and soil moisture content (SMC) over sampling times (between January 2017 and June 2018). Data are average values of 12 sampling points.

\subsection{Evolution of Pasture Parameter Patterns Throughout the Vegetative Cycle}

According to Zhao et al. [22], grassland biomass and quality are the main direct indicators of grassland's ecological status. Table 2 shows the evolution of the mean pasture parameters (biomass, PMC, CP, NDF and PQDI) of the "Mitra" experimental field in three consecutive springs (2016-2018).

Table 2. Descriptive statistics (mean \pm standard deviation) of pasture parameters, measured at the 12 sampling points of the studied field, for each sampling date (between February or March and June) of 2016-2018.

\begin{tabular}{|c|c|c|c|c|c|c|}
\hline Parameters & DOY & $\begin{array}{l}\text { Biomass } \\
\left(\mathrm{kg} \cdot \mathrm{ha}^{-1}\right)\end{array}$ & $\begin{array}{c}\text { PMC } \\
(\%)\end{array}$ & $\begin{array}{l}\text { CP } \\
(\%)\end{array}$ & $\begin{array}{l}\text { NDF } \\
(\%)\end{array}$ & PQDI \\
\hline \multicolumn{7}{|l|}{2016} \\
\hline March & 80 & $14,106 \pm 7095$ & $85.8 \pm 2.6$ & $12.8 \pm 1.6$ & $36.2 \pm 4.1$ & $2.8 \pm 0.4$ \\
\hline April & 120 & $21,403 \pm 9128$ & $85.9 \pm 1.3$ & $10.5 \pm 1.8$ & $50.5 \pm 5.5$ & $5.1 \pm 1.5$ \\
\hline May & 150 & $33,149 \pm 13,221$ & $88.0 \pm 4.0$ & $8.6 \pm 2.2$ & $64.5 \pm 2.9$ & $8.1 \pm 2.7$ \\
\hline June & 160 & $11,023 \pm 3888$ & $60.5 \pm 6.9$ & $7.7 \pm 1.3$ & $65.1 \pm 5.0$ & $10.1 \pm 2.6$ \\
\hline \multicolumn{7}{|l|}{2017} \\
\hline February & 50 & $6300 \pm 3802$ & $71.0 \pm 13.6$ & $14.2 \pm 3.5$ & $51.2 \pm 12.9$ & $4.0 \pm 2.1$ \\
\hline March & 80 & $11,292 \pm 6041$ & $79.7 \pm 5.0$ & $14.8 \pm 3.2$ & $49.6 \pm 7.8$ & $3.5 \pm 1.2$ \\
\hline April & 110 & $14,567 \pm 8440$ & $66.2 \pm 5.8$ & $9.4 \pm 1.3$ & $60.4 \pm 5.1$ & $8.5 \pm 1.9$ \\
\hline May & 140 & $5767 \pm 2178$ & $47.9 \pm 8.4$ & $7.7 \pm 1.2$ & $72.7 \pm 3.7$ & $9.7 \pm 2.0$ \\
\hline June & 165 & $1725 \pm 763$ & $14.7 \pm 4.8$ & $5.4 \pm 0.8$ & $78.1 \pm 2.6$ & $14.9 \pm 2.5$ \\
\hline \multicolumn{7}{|l|}{2018} \\
\hline February & 40 & $3973 \pm 3193$ & $76.2 \pm 8.9$ & $15.9 \pm 4.5$ & $33.5 \pm 15.3$ & $2.5 \pm 1.9$ \\
\hline March & 50 & $7587 \pm 5448$ & $80.9 \pm 6.5$ & $15.0 \pm 3.0$ & $33.8 \pm 10.8$ & $2.5 \pm 1.4$ \\
\hline April & 100 & $16,880 \pm 11,256$ & $83.6 \pm 2.3$ & $10.8 \pm 2.0$ & $37.7 \pm 6.5$ & $3.6 \pm 0.9$ \\
\hline May & 125 & $11,833 \pm 4566$ & $81.7 \pm 3.1$ & $14.0 \pm 3.2$ & $44.7 \pm 7.0$ & $3.4 \pm 1.1$ \\
\hline June & 150 & $15,990 \pm 5800$ & $70.6 \pm 3.1$ & $9.1 \pm 1.5$ & $59.2 \pm 4.3$ & $6.7 \pm 1.3$ \\
\hline
\end{tabular}

DOY - day of the year; PMC—pasture moisture content; $\mathrm{CP}$ - pasture crude protein; NDF-pasture neutral detergent fiber; PQDI-pasture quality degradation index. 
Taking into account the marked climatic seasonality in the Mediterranean area, a three-year period was selected to cover diverse seasonal cycles, and therefore, study a wide variety of climate and, consequently, of SMC situations. Figure 5a shows the evolution of pasture productivity (biomass) in spring of 2016, 2017 and 2018. As expected in dryland pastures, this evolution reflects the effect of rainfall distribution (Figure 6a,b). It is evident that the most productive spring (2016) was one in which rainfall was evenly distributed in autumn, winter and spring (2015-2016).
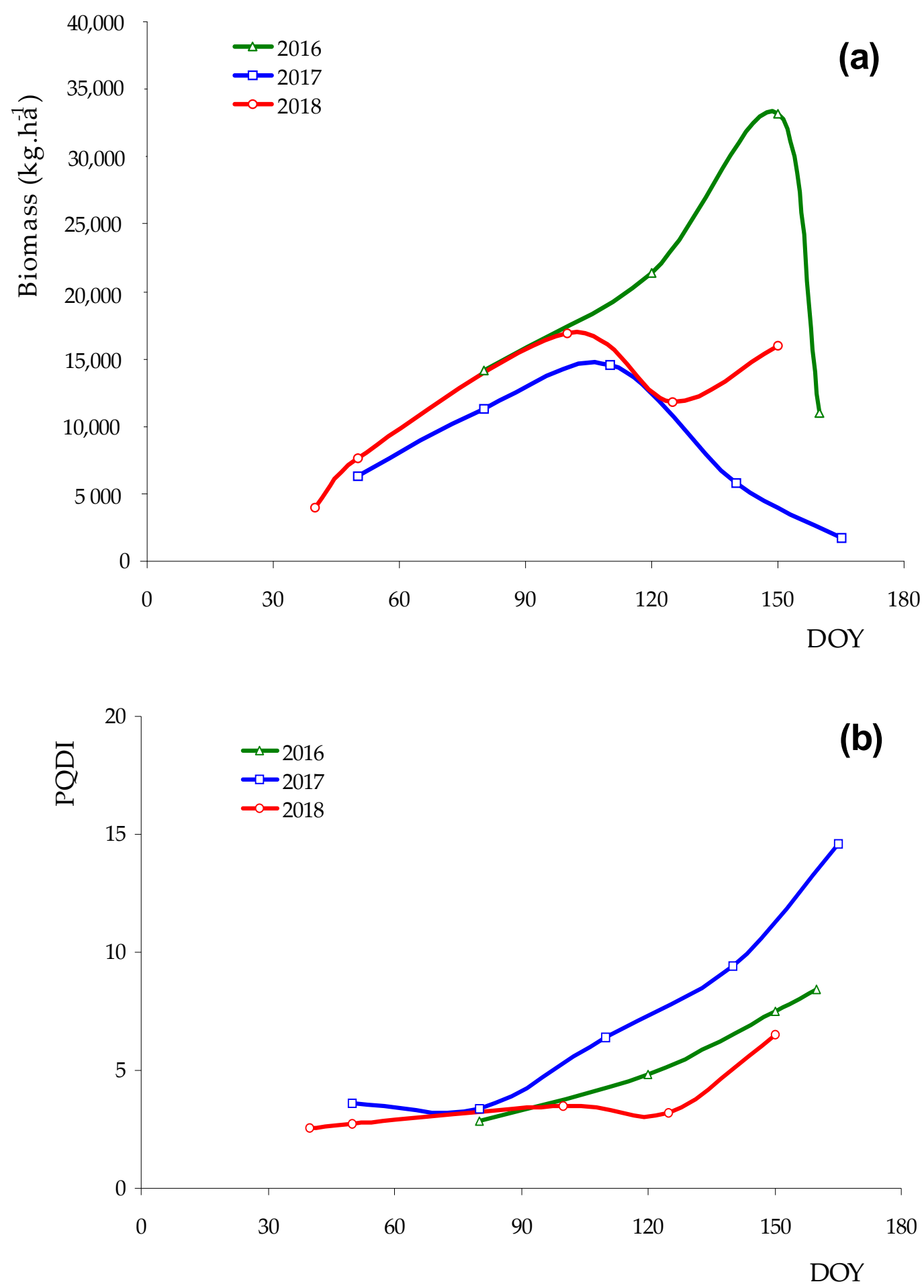

Figure 5. Evolution of pasture productivity (biomass, (a)) and pasture quality degradation index (PQDI, (b)) in three consecutive springs (2016-2018). Data are average values of the 12 sampling points. 

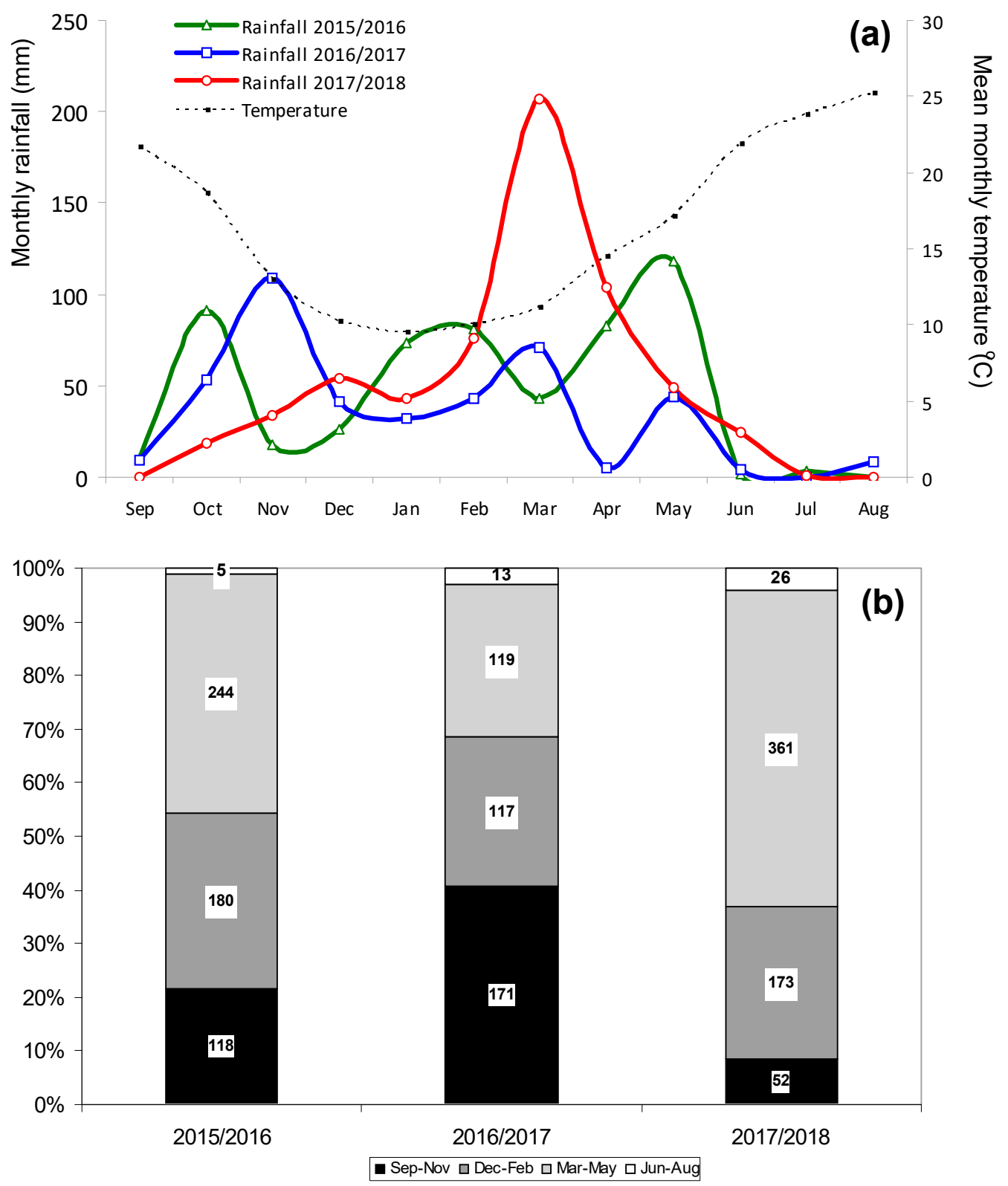

Figure 6. Monthly evolution of rainfall and mean temperature (a); and quarterly accumulated rainfall (b; in mm and \%) over three years (2015-2016; 2016-2017 and 2017-2018) in "Mitra" experimental field.

The productivity in February-March (at the end of winter) is the baseline resulting from the plant growth provided by the meteorological conditions of autumn, since the low temperatures of winter (between December and February in Mediterranean region), with minimum temperature below $10^{\circ} \mathrm{C}$, lead to a period of plant dormancy which affects grassland biomass [16].

The agricultural year of September 2015-August 2016, with an accumulated rainfall of $547 \mathrm{~mm}$, can be considered "a relatively balanced year". The peak rainfall in October allowed the germination and growth of the pasture. The regular rainfall during winter and spring (with a precipitation peak in May), ensured sufficient $S M C$ which, in association with favourable air temperature, lengthened the growth cycle of the pasture. After the production peak of spring, which in 2016 occurred at the beginning of May (Table 2), an important decrease of PMC was observed, which reflects the corresponding loss of pasture quality. The biomass production curve in 2016 is typical of years with a balanced rainfall distribution under the Mediterranean conditions of Alentejo [4]. 
The agricultural year September 2016-August 2017, with an accumulated rainfall of only $421 \mathrm{~mm}$ can be considered "a relatively dry year". Despite the rainy autumn (with $171 \mathrm{~mm}$ of accumulated rainfall between September and November; Figure 6b), which provided the necessary conditions for initial development of pasture, the winter and spring were relatively dry (with only $236 \mathrm{~mm}$ of rainfall in the six-month period of December to May), which compromised the peak vegetative growth and pasture productivity in the spring. The decrease in productivity started in the month of April, from DOY 100 (Figure 5a).

The agricultural year September 2017-August 2018 can be considered "a relatively unbalanced year" since despite an accumulated rainfall of $612 \mathrm{~mm}$, the autumn was relatively dry, with only $52 \mathrm{~mm}$ of accumulated rainfall between September and November (Figure 6b). This lack of rainfall at the start of pasture growth compromised its autumn development and, consequently, the spring development. Thus, the high concentration of rainfall in the spring (with $361 \mathrm{~mm}$ of accumulated rainfall between March and May, Figure 6b), proved to be too late, and did not lead to an increase in productivity due to the advanced stage of plant development. This accumulated rainfall and the consequent increase in the soil moisture, nonetheless prolonged the growth stage of the pasture, causing the definite decrease in productivity to happen only after DOY 150 (in June; Figure 5a).

These results indicate that climatic factors such as precipitation and temperature affect the spatial distribution and inter-annual fluctuation of biomass [23]. According to Gao et al. [24], the year-to-year biomass production pattern is generally consistent with the inter-annual variation in the growing season precipitation, but an opposite coupled pattern is observed with the growing season temperature.

This inter-annual variability introduces an uncertainty factor for the farm manager, and can affect the dynamic management of grazing and fertilization.

The effect of the agricultural year (in terms of rainfall distribution) is also visible in the quality of the pasture (CP and NDF, Table 2). According to Sala and Parton [25], precipitation is an essential factor in controlling biodiversity and ecosystem stability of terrestrial biomes, especially in the case of arid and semiarid ecosystems. Figure 5b shows the evolution of PQDI in the spring of 2016, 2017 and 2018. Since PQDI is the result of the ratio between NDF and CP, its evolution, although variable from year to year, shows the general tendency for a decrease in the quality of pasture, as the growth cycle of Mediterranean pastures evolves [4]. The degradation of the pasture quality in June $2017(\mathrm{PQDI}=14.9)$ at the end of the spring of a dry year is particularly significant, as it emphasizes the importance of rainfall for prolonging the nutritive value of pasture. According to Gu et al. [8] soil moisture is a critical component in land surface atmospheric processes and prolonged soil moisture deficits often lead to drought induced vegetation stress. This stage of greater degradation of pasture quality at the end of spring, also observed by Chakround et al. [2], begins, on average, from the beginning of the month of May (DOY 120; Figure 5b), but can begin at different times depending on the weather. It is a key moment for the farm manager in terms of anticipation of the need to provide feed supplements [10] and a determining factor in terms of grazing dynamics.

\subsection{Satellite-Derived Normalized Difference Water Index (NDWI) and Normalized Difference Vegetation Index (NDVI) Time Series}

Table 3 shows the evolution of the mean NDWI and NDVI at the first semester of 2016, all the year of 2017, and in the first semester of 2018. A total of 41 valid records are presented (a preliminary screening was carried out to remove outliers due to existence of clouds). The highest temporal frequency ( 5 days) of records observed in 2018 (relative to the temporal resolution of 10 days in 2016 and 2017) provided a larger number of valid records (without cloud interference) in this year, increasing the interest and the potential of these indexes in monitoring crop development. 
Table 3. Descriptive statistics (mean \pm standard deviation) of NDWI and NDVI captured at the 12 sampling points of the studied field, for each sampling date, between January and June 2016 and between January 2017 and June 2018.

\begin{tabular}{|c|c|c|c|}
\hline Year (Valid Records) & DOY & NDWI & NDVI \\
\hline \multirow{7}{*}{$\begin{array}{c}2016 \\
\text { 1st semester } \\
(7)\end{array}$} & 80 & $0.471 \pm 0.008$ & $0.624 \pm 0.025$ \\
\hline & 120 & $0.494 \pm 0.016$ & $0.687 \pm 0.039$ \\
\hline & 140 & $0.401 \pm 0.014$ & $0.615 \pm 0.025$ \\
\hline & 150 & $0.517 \pm 0.022$ & $0.478 \pm 0.044$ \\
\hline & 160 & $0.185 \pm 0.032$ & $0.413 \pm 0.018$ \\
\hline & 170 & $0.040 \pm 0.036$ & $0.379 \pm 0.050$ \\
\hline & 180 & $-0.022 \pm 0.020$ & $0.318 \pm 0.031$ \\
\hline \multirow{10}{*}{$\begin{array}{c}2017 \\
\text { 1st semester } \\
(10)\end{array}$} & 15 & $0.231 \pm 0.031$ & $0.610 \pm 0.090$ \\
\hline & 50 & $0.240 \pm 0.040$ & $0.576 \pm 0.059$ \\
\hline & 80 & $0.358 \pm 0.036$ & $0.640 \pm 0.039$ \\
\hline & 95 & $0.318 \pm 0.054$ & $0.675 \pm 0.040$ \\
\hline & 110 & $0.254 \pm 0.046$ & $0.596 \pm 0.051$ \\
\hline & 140 & $-0.002 \pm 0.035$ & $0.340 \pm 0.052$ \\
\hline & 155 & $-0.079 \pm 0.039$ & $0.311 \pm 0.055$ \\
\hline & 165 & $-0.086 \pm 0.027$ & $0.261 \pm 0.048$ \\
\hline & 175 & $-0.067 \pm 0.018$ & $0.224 \pm 0.024$ \\
\hline & 180 & $-0.018 \pm 0.017$ & $0.118 \pm 0.027$ \\
\hline \multirow{6}{*}{$\begin{array}{c}2017 \\
\text { 2nd semester } \\
\quad(6)\end{array}$} & 195 & $-0.126 \pm 0.024$ & $0.250 \pm 0.038$ \\
\hline & 215 & $-0.108 \pm 0.019$ & $0.232 \pm 0.040$ \\
\hline & 255 & $-0.129 \pm 0.013$ & $0.234 \pm 0.049$ \\
\hline & 290 & $0.007 \pm 0.019$ & $0.242 \pm 0.062$ \\
\hline & 330 & $-0.001 \pm 0.064$ & $0.372 \pm 0.089$ \\
\hline & 345 & $0.098 \pm 0.040$ & $0.478 \pm 0.047$ \\
\hline \multirow{18}{*}{$\begin{array}{c}2018 \\
\text { 1st semester } \\
\quad(18)\end{array}$} & 15 & $0.192 \pm 0.022$ & $0.568 \pm 0.079$ \\
\hline & 40 & $0.205 \pm 0.076$ & $0.624 \pm 0.047$ \\
\hline & 50 & $0.255 \pm 0.051$ & $0.560 \pm 0.045$ \\
\hline & 65 & $0.247 \pm 0.081$ & $0.654 \pm 0.051$ \\
\hline & 80 & $0.414 \pm 0.044$ & $0.732 \pm 0.043$ \\
\hline & 85 & $0.427 \pm 0.050$ & $0.721 \pm 0.036$ \\
\hline & 90 & $0.465 \pm 0.049$ & $0.633 \pm 0.063$ \\
\hline & 100 & $0.430 \pm 0.036$ & $0.695 \pm 0.033$ \\
\hline & 110 & $0.442 \pm 0.020$ & $0.591 \pm 0.025$ \\
\hline & 120 & $0.425 \pm 0.025$ & $0.667 \pm 0.038$ \\
\hline & 125 & $0.452 \pm 0.013$ & $0.718 \pm 0.015$ \\
\hline & 130 & $0.445 \pm 0.020$ & $0.709 \pm 0.018$ \\
\hline & 135 & $0.398 \pm 0.024$ & $0.685 \pm 0.033$ \\
\hline & 150 & $0.449 \pm 0.038$ & $0.397 \pm 0.043$ \\
\hline & 165 & $0.091 \pm 0.024$ & $0.356 \pm 0.026$ \\
\hline & 170 & $0.002 \pm 0.024$ & $0.300 \pm 0.042$ \\
\hline & 175 & $-0.055 \pm 0.023$ & $0.271 \pm 0.038$ \\
\hline & 180 & $-0.014 \pm 0.021$ & $0.248 \pm 0.042$ \\
\hline
\end{tabular}

DOY—day of the year; NDWI—normalized difference water index; NDVI—normalized difference vegetation index.

Despite inter-annual differences, the general trend consists of a rise in NDWI and NDVI values at the beginning of spring, reaching a maximum value during April (DOY 90-120), followed by a clear decrease. This pattern, typical of dryland ecosystems, reflects the conjugation of the effects of air temperature and precipitation and their influence on SMC, PMC and vegetative vigour. Vegetation index, NDVI, is responsive to changes in both the chlorophyll content and the intracellular spaces in spongy mesophyll of plant leaves: higher NDVI values reflect greater vigour and photosynthetic capacity of vegetation, whereas lower NDVI values are reflective of vegetative stress resulting in chlorophyll reductions and changes in the leaves' internal structure due to wilting [8]. On the other 
hand, NDWI responds to changes in both the water content and spongy mesophyll in vegetation that interacts with the incoming solar radiation [11].

3.4. Correlation between NDWI and NDVI, SMC, $T_{\text {ir }}$, Pasture Moisture Content (PMC), Biomass and Pasture Quality Degradation Index (PQDI)

Figure 7 shows the strong and significant correlation between NDWI and NDVI $\left(R^{2}=0.8621\right.$; $p<0.01$ ) in the set of 41 sampling moments considered in Table 3 (between January and June 2016 and between January 2017 and June 2018), as was also observed in other works [8,11]. Serrano et al. [10] obtained strong and significant correlations between NDVI, which is mainly related to canopy chlorophyll content [14] and pasture quality (NDF, CP and PQDI), showing that this index can be of great interest in creating a system of alarms for the farm manager indicating the need to provide supplementary animal feed. In view of the great influence of SMC and of $T_{i r}$ on the physiological processes that are responsible for biomass production, a more specific index was evaluated in this work. Water index (NDWI) is sensitive to changes in liquid water content of vegetation and, thus, must be viewed not as a replacement of NDVI, but as a way to complement it, as was also proposed by [11].

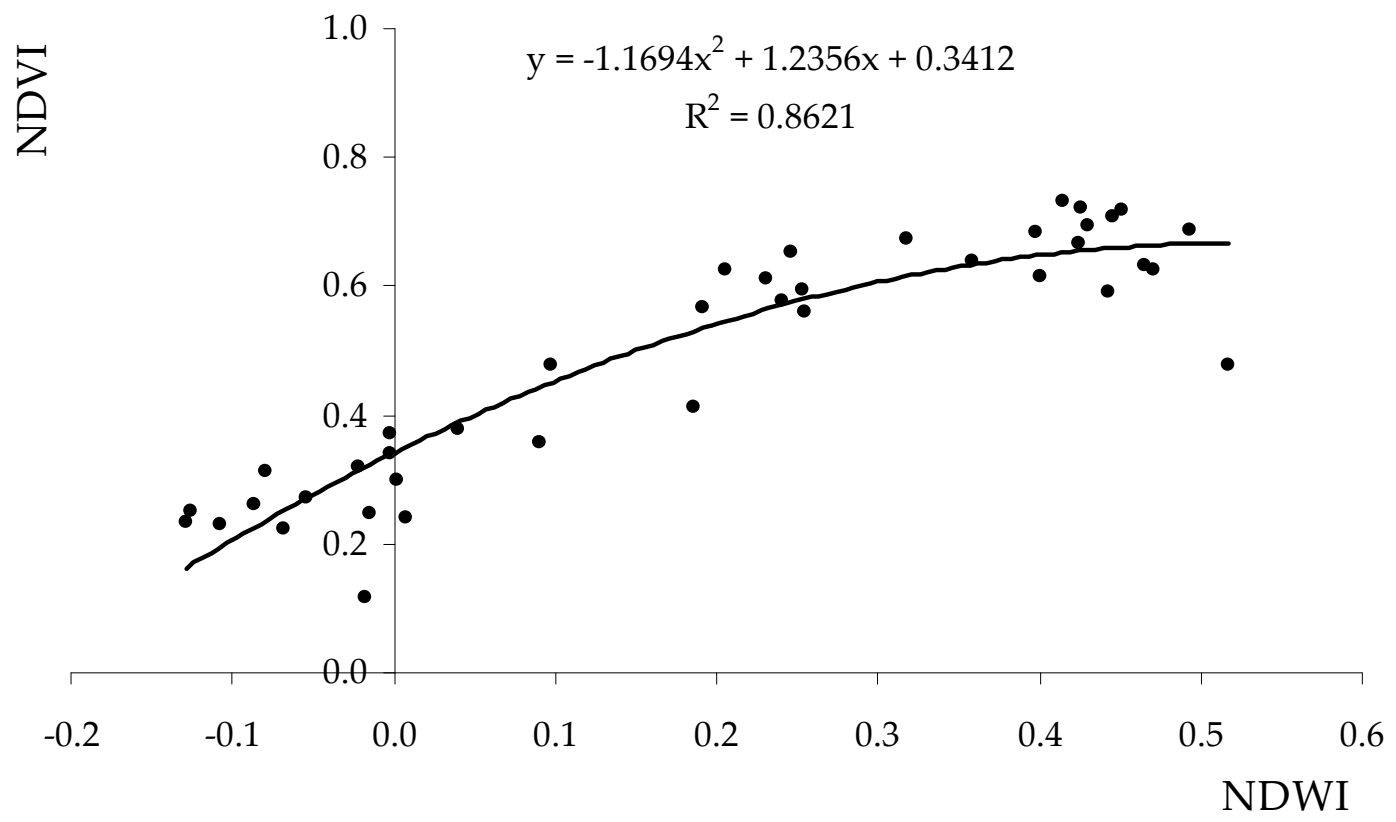

Figure 7. Relationship between normalized difference vegetation index (NDVI) and normalized difference water index (NDWI) over sampling times (between January and June 2016 and between January 2017 and June 2018). Data are average values of 12 sampling points.

Continued evaluation of satellite-derived NDWI for vegetation drought monitoring using ground observations (e.g., SMC) is required to better understand how this index responds to soil moisture fluctuations, which is ultimately tied to drought stress in plants [8]. According to Sanchez-Ruiz et al. [5], SMC measured at 10-20 cm depth is regarded as a proxy of the water availability for pasture photosynthetic activity, due to its shallow root depth. Figure 8 shows the temporal tracking of SMC, $T_{\text {ir }}$ and spectral NDWI measurements between January 2017 and June 2018. A great similarity can be observed between the NDWI and SMC profiles, while $T_{i r}$ has an inverse tendency. If we take as reference the minimum $\mathrm{T}_{\text {ir }}$ of $10{ }^{\circ} \mathrm{C}$ (shown as a red dotted line in Figure 8), below which plants enter dormancy [4], we can determine the most favourable periods $\left(\mathrm{T}_{\mathrm{ir}}>10^{\circ} \mathrm{C}\right.$ and SMC $>10 \%$ ) for the plants to access the nutrients needed for their growth. Figure 8 shows that these occasions take place in March (spring of 2017) or April (spring 2018), which are both associated with peaks of NDWI. Thus this index seems to serve as an interesting indicator for supporting decision 
making by the farm manager in terms of the timing of application of topdressing fertilizer, which is a very common practice in the region for improving the pastures.

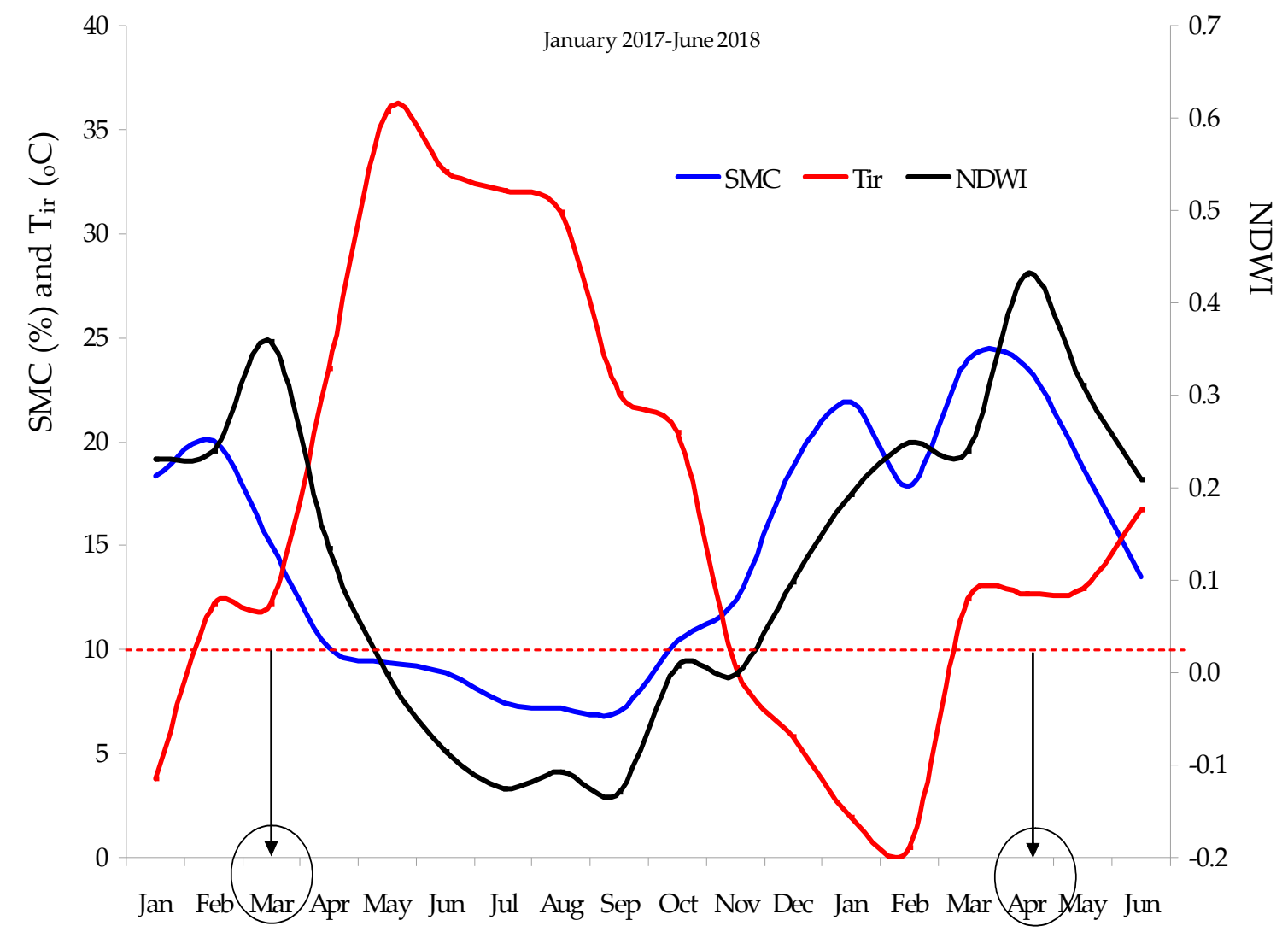

Figure 8. Monthly evolution, between January 2017 and June 2018, of soil moisture content (SMC), pasture surface temperature $\left(\mathrm{T}_{\mathrm{ir}}\right)$ and normalized difference water index (NDWI). Data are average values of the 12 sampling points. The red dashed line corresponds to the $\mathrm{T}_{\text {ir }}$ of $10^{\circ} \mathrm{C}$.

Figure 9 shows the relationship between SMC and NDWI and between $\mathrm{T}_{\mathrm{ir}}$ and NDWI along the sampling times (between January 2017 and June 2018). The significant correlation between NDWI and SMC $\left(R^{2}=0.7548 ; p<0.01\right)$ shows that satellite-derived NDWI is valid for monitoring SMC, which confirms previous works [2,8,11]. These results corroborate the findings of Wang et al. [15] which suggests that shortwave infrared (SWIR) band of the "water index" (NDWI) captures important information on seasonally variable water status throughout the vegetative cycle of pastures. This relation is particularly interesting in water-limited regions, which is the case of the Mediterranean region, where it is essential to determine the main constraints of the ecosystem [2].

Having verified the correlation of NDWI with SMC, and evaluated NDWI as a "water index" [8,11], associated to canopy water content and soil moisture [14], sensitive to the total amount of liquid water in the leaves [11], the next step is to evaluate the correlation between this index and PMC (Figure 10). The great similarity of patterns of the temporal variability of PMC and spectral NDWI (average monthly values measured between February or March and June of three successive years, 2016-2018) indicates that NDWI describes the status of the vegetation moisture content, which is often a function of local climate and soil properties controlling water availability [5]. These results are in agreement with the considerations of Sanchez-Ruiz et al. [5] that the spectral signature of vegetation in NIR and SWIR bands can be associated with the plant water status. The NDWI is sensitive to changes in leaf water content because green vegetation spectra in the SWIR region is dominated by water absorption effects [5], whereby, the quantity of leaf material can be known in order to estimate vegetation dryness [26]. 


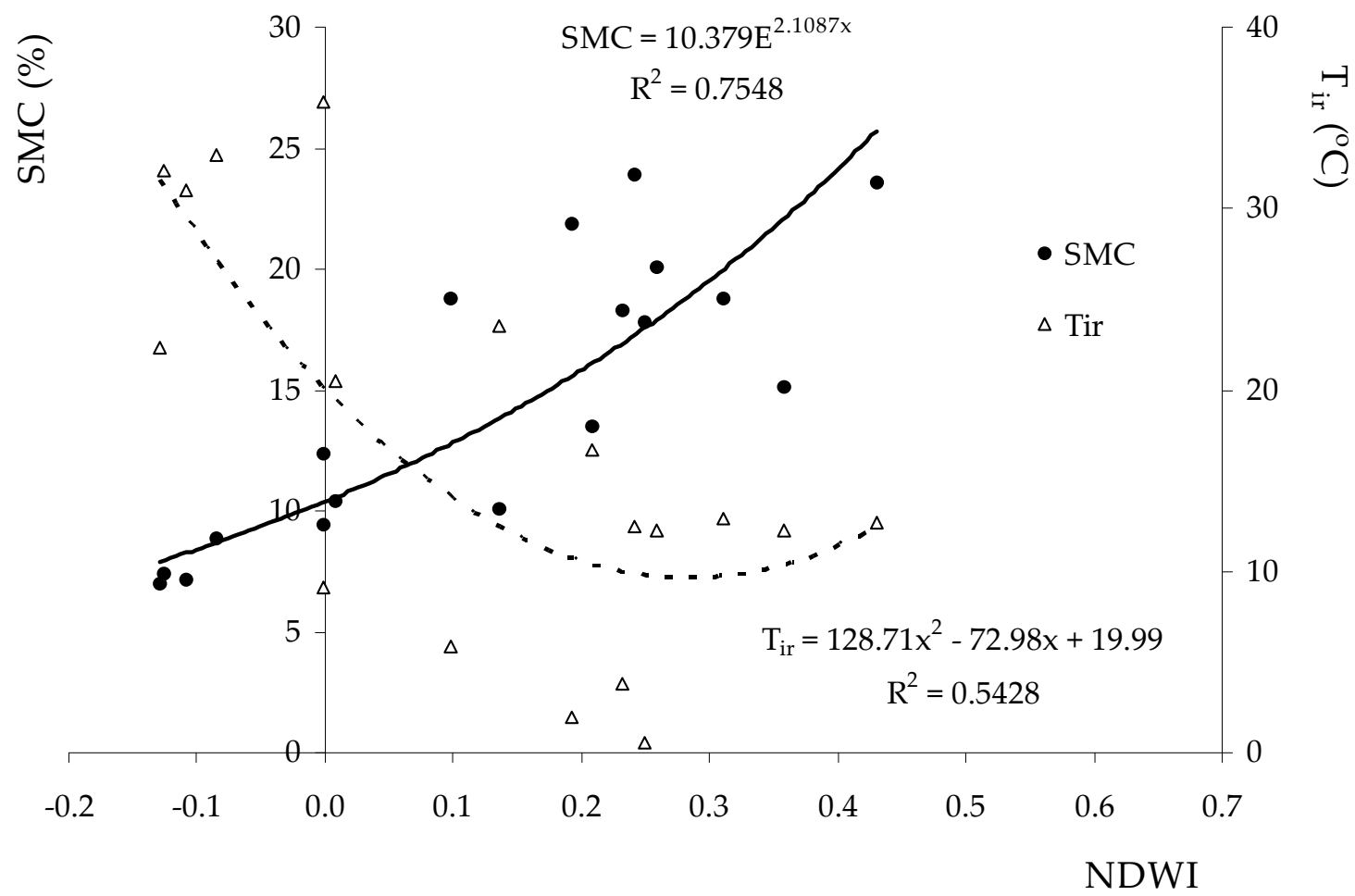

Figure 9. Relationship between normalized difference water index (NDWI), soil moisture content (SMC) and pasture surface temperature $\left(\mathrm{T}_{\text {ir }}\right)$ over sampling times (between January 2017 and June 2018). Data are average values of 12 sampling points.

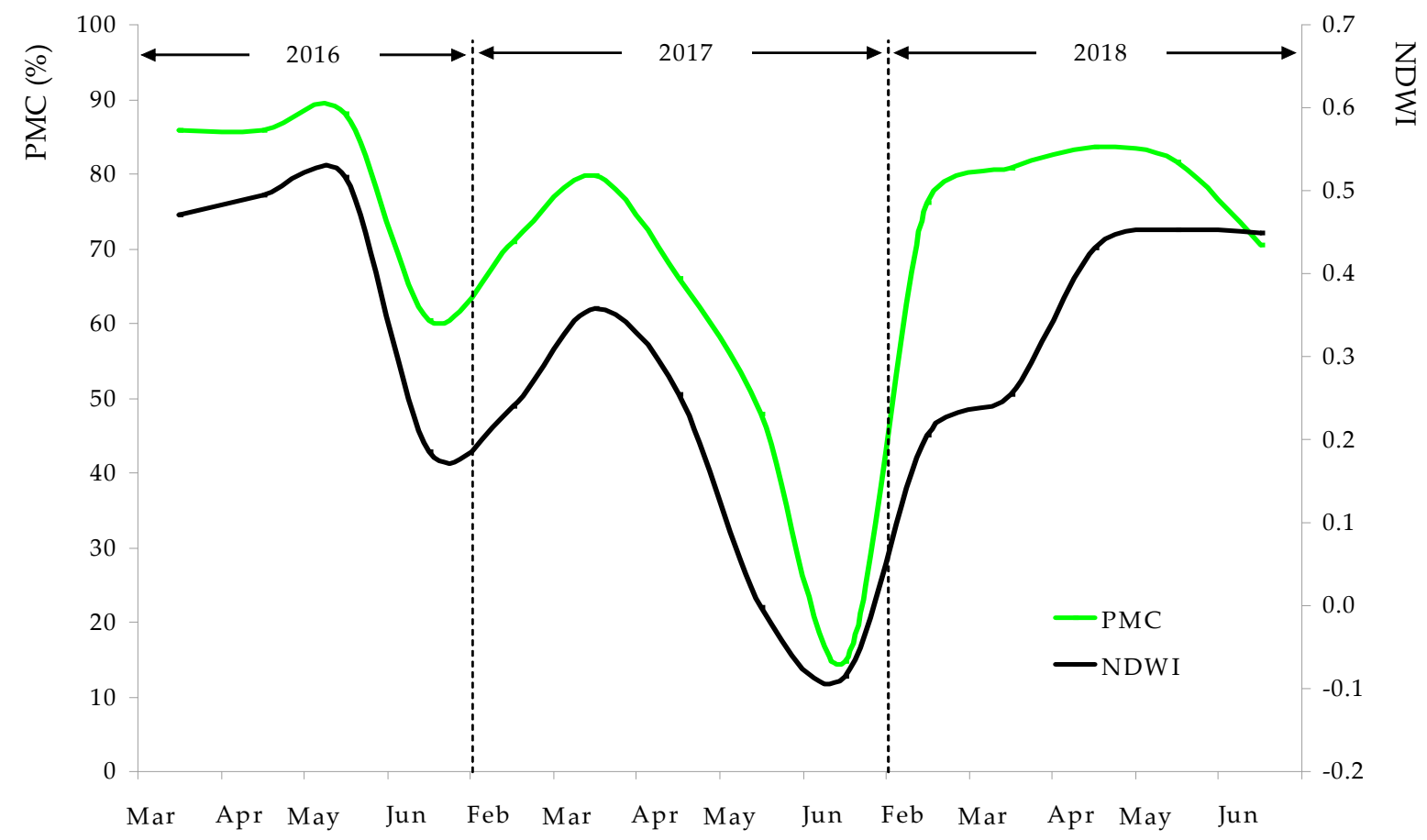

Figure 10. Monthly evolution of pasture moisture content (PMC) and normalized difference water index (NDWI) in three consecutive springs (2016-2018). Data are average values of the 12 sampling points.

Figure 11 shows the relationship between NDWI and PMC and between NDWI and PQDI. Pasture moisture content is a parameter indicative of plant vegetative vigour, with a tendency to decease at the end of the growth cycle. In the case of "relatively dry year" (2017), PMC in June was extremely low 
$(14.7 \pm 4.8 \%)$, corresponding, as mentioned above, to the highest value of PQDI (14.9 \pm 2.5$)$. These two parameters (PMC and PQDI), have, thus an inverse behaviour in the relation with NDWI (Figure 11), although both with significant determination coefficients $\left(R^{2}=0.8938 ; p<0.01\right.$ to $P M C ; R^{2}=0.7333$; $p<0.01$ to PQDI).

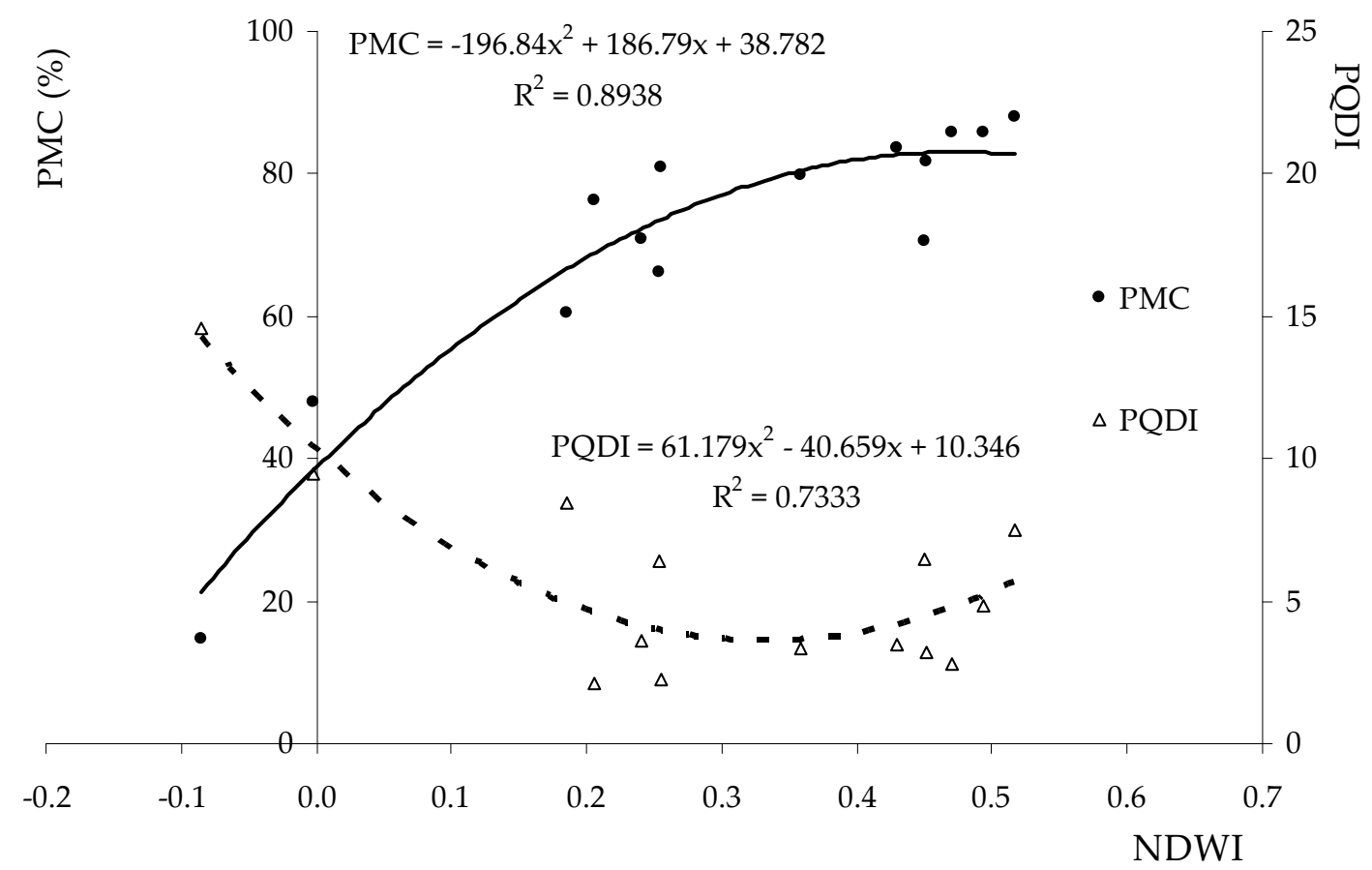

Figure 11. Relationship between normalized difference water index (NDWI), pasture moisture content (PMC) and pasture quality degradation index (PQDI) over sampling times (springs 2016-2018). Data are average values of the 12 sampling points.

Figure 12 shows the relationship between NDWI and biomass. The resulting curve has a tendency for over-saturation, and consequently a decline in the accuracy/sensitivity of this index at high values of biomass (above 20,000 kg.ha ${ }^{-1}$ ), an aspect documented in various works related to NDVI ([10,22,27-30]. These results show that NDWI based on remote sensing can be an interesting tool to estimate pasture biomass $\left(\mathrm{R}^{2}=0.7556 ; p<0.01\right)$. Pasture biomass is a vital input for the management of dairy systems, allowing the calculation of feed budget, based on which decisions are made for farm practices such as rotational lengths and supplementary feeding, leading to profitability and a sustainable use of pasture resources [31].

In comparison with the use of NDVI in pastures [10], these results suggest that NDWI has a more broad application potential, and is appropriate for monitoring drought stress in vegetation, through plant available water (SMC), light-harvesting capacity (biomass) or crop progress and vegetation health (PMC and PQDI, respectively) [19]. The response to the level of SMC and $\mathrm{T}_{\text {ir }}$ is particularly important, since these parameters are drivers of dryland pasture growth [28].

In summary, the practical interest of this study is related with the integration of satellite-derived NDWI and NDVI in site-specific management of the "montado" ecosystem This information can support the decision making process when the farmer intends to intensify the production (irrigation or fertilization management, animal feed supplementation or dynamic grazing management), based on soil moisture content (SMC) and pasture productivity (biomass) and quality (CP, NDF, PQDI and PMC) monitoring. 


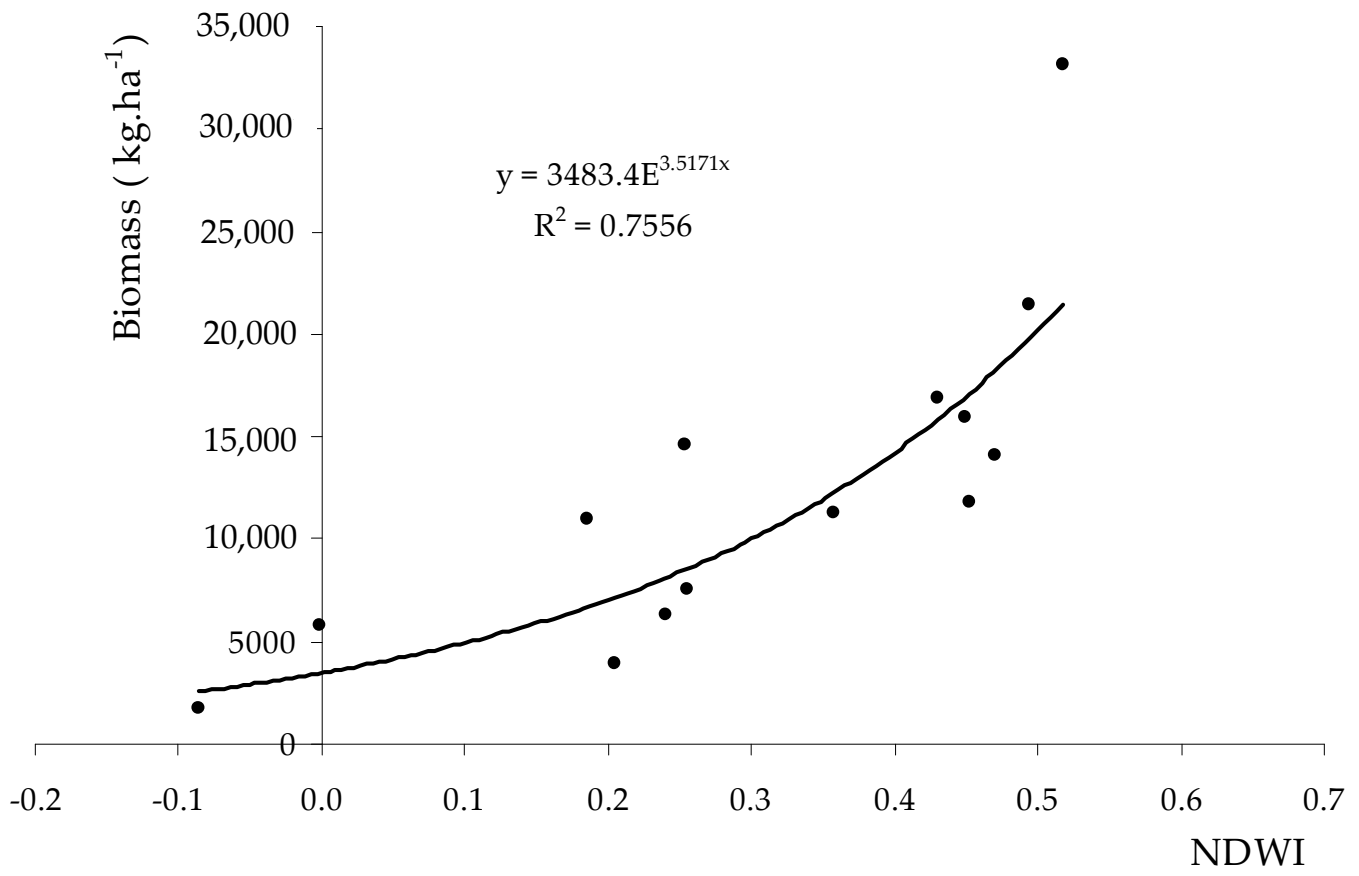

Figure 12. Relationship between normalized difference water index (NDWI) and pasture biomass, over sampling times (springs 2016-2018). Data are average values of 12 sampling points.

\section{Conclusions}

In the Iberian Peninsula, dryland natural pastures are the basis of animal feeding under extensive production regimes. The annual climatic seasonality, associated to inter-annual irregularity of precipitation in this semi-arid region, affects soil moisture content and surface pasture temperature, driver factors of vegetation development. This work demonstrates that remote sensing can provide valuable large-scale spatial and temporal information about yield-limiting factors and crop response under current and variable climate conditions. The normalized difference water index (NDWI) shows strong and significant correlations with soil moisture content $\left(R^{2}=0.7548\right)$, pasture moisture content $\left(R^{2}=0.8938\right)$, surface pasture temperature $\left(R^{2}=0.5428\right)$, biomass productivity $\left(R^{2}=0.7556\right)$ and pasture quality degradation index $\left(R^{2}=0.7333\right)$. These findings suggest that satellite-derived NDWI can be used in site-specific management of the "montado" ecosystem, as an indicator of critical importance for monitoring and predicting deterioration/restoration of pasture and to support decision making related to agronomic practices for the sustainable use of grassland resources. These decisions include differential soil amendment or fertilization, pasture irrigation, or dynamic grazing. This can be an interesting research topic allowing the assessment of dryness or drought stress on vegetation in Mediterranean-type ecosystems through plant available water, light-harvesting capacity or vegetation health, with applications in other important crops in the region, such as the vineyard or the olive grove. However, given the complexity and number of variables involved, future research deserves more detailed and deeper inquiry, especially to find the most specific and valid indices for each situation.

Author Contributions: J.S.: conceptualization, literature review, planning and execution of experimental work, processing of data, discussion of results, and writing original draft of this manuscript. S.S.: discussion of results and final revision/edition of the English. J.M.d.S.: processing of data and discussion of results.

Funding: This work was funded by National Funds through FCT (Foundation for Science and Technology) under the Project UID/AGR/00115/2013, and by the project INNOACE-Innovación abierta e inteligente en la EUROACE (Tarea 2.1.3).

Acknowledgments: The authors would like to express their sincere appreciation to Emanuel Carreira and Graça Machado of the Animal Production Department of the University of Évora for their support in, respectively, collection and analysis of data of pasture. They would also like to express their sincere appreciation to Luís Paixão for her support in data collection of satellite images. 
Conflicts of Interest: The authors declare no conflict of interest.

\section{References}

1. David, T.; Pinto, C.; Nadezhdina, N.; Kurz-Besson, C.; Henriques, M.; Quilhó, T.; Cermak, J.; Chaves, M.; Pereira, J.; David, J. Root functioning, tree water use and hydraulic redistribution in Quercus suber trees: A modeling approach based on root sap flow. For. Ecol. Manag. 2013, 307, 136-146. [CrossRef]

2. Chakroun, H.; Mouillot, F.; Hamdi, A. Regional equivalent water thickness modeling from remote sensing across a tree cover/LAI gradient in Mediterranean forests of Northern Tunisia. Remote Sens. 2015, 7, 1937-1961. [CrossRef]

3. Piragnolo, M.; Pirotti, F.; Guarnieri, A.; Vettore, A.; Salogni, G. Geo-spatial support for assessment of anthropic impact on biodiversity. Int. J. Geo-Inf. 2014, 3, 599-618. [CrossRef]

4. Efe Serrano, J. Pastures in Alentejo: Technical Basis for Characterization, Grazing and Improvement; Universidade de Évora: Évora, Portugal, 2006.

5. Sánchez-Ruiz, S.; Piles, M.; Sánchez, N.; Martínez-Fernández, J.; Vall-llossera, M.; Camps, A. Combining SMOS with visible and near/shortwave/thermal infrared satellite data for high resolution soil moisture estimates. J. Hidrol. 2014, 516, 273-283. [CrossRef]

6. Chai, X.; Zhang, T.; Shao, Y.; Gong, H.; Liu, L.; Xie, K. Modeling and mapping soil moisture of plateau pasture using RADARSAT-2 imagery. Remote Sens. 2015, 7, 1279-1299. [CrossRef]

7. Serrano, J.; Shahidian, S.; Marques da Silva, J. Spatial variability and temporal stability of apparent soil electrical conductivity in a Mediterranean pasture. Precis. Agric. 2017, 18, 245-263. [CrossRef]

8. Gu, Y.; Hunt, E.; Wardlow, B.; Basara, J.B.; Brown, J.F.; Verdin, J.P. Evaluation of MODIS NDVI and NDWI for vegetation drought monitoring using Oklahoma Mesonet soil moisture data. Geophys. Res. Lett. 2008, 35, L22401. [CrossRef]

9. Serrano, J.; Shahidian, S.; Marques da Silva, J. Calibration of GrassMaster II to estimate green and dry matter yield in Mediterranean pastures: Effect of pasture moisture content. Crop Pasture Sci. 2016, 67, 780-791. [CrossRef]

10. Serrano, J.; Shahidian, S.; Marques da Silva, J. Monitoring seasonal pasture quality degradation in the Mediterranean montado ecosystem: Proximal versus remote sensing. Water 2018, 10, 1422. [CrossRef]

11. Gao, B.-C. NDWI-A normalized difference water index for remote sensing of vegetation liquid water from space. Remote Sens. Environ. 1996, 58, 257-266. [CrossRef]

12. Pullanagari, R.R.; Kereszturi, G.; Yule, I. Integrating airborne hyperspectral, topographic, and soil data for estimating pasture quality using recursive feature elimination with random forest regression. Remote Sens. 2018, 10, 1117. [CrossRef]

13. Georgi, C.; Spengler, D.; Itzerott, S.; Kleinschmit, B. Automatic delineation algorithm for site-specific management zones based on satellite remote sensing data. Precis. Agric. 2018, 19, 684-707. [CrossRef]

14. Jackson, T.J.; Chen, D.; Cosh, M.; Li, F.; Anderson, M.; Walthall, C.; Doriaswamy, P.; Hunt, E.R. Vegetation water content mapping using Landsat data derived normalized difference water index for corn and soybeans. Remote Sens. Environ. 2004, 92, 475-482. [CrossRef]

15. Wang, X.; Fuller, D.O.; Setemberg, L.; Miralles-Wilhelm, F. Foliar nutrient and water content in subtropical tree islands: A new chemohydrodynamic link between satellite vegetation indices and foliar $\delta^{15} \mathrm{~N}$ values. Remote Sens. Environ. 2011, 3, 923-930. [CrossRef]

16. FAO. World Reference Base for Soil Resources; Food and Agriculture Organization of the United Nations, World Soil Resources Reports No. 103; IUSS Working Group WRB: Rome, Italy, 2006.

17. Serrano, J.; Shahidian, S.; Marques da Silva, J.; Sales-Baptista, E.; Ferraz de Oliveira, I.; Lopes de Castro, J.; Pereira, A.; Cancela de Abreu, M.; Machado, E.; Carvalho, M. Tree influence on soil and pasture: Contribution of proximal sensing to pasture productivity and quality estimation in montado ecosystems. Int. J. Remote Sens. 2018, 39, 4801-4829. [CrossRef]

18. AOAC. AOAC Official Methods of Analysis of AOAC International, 18th ed.; AOAC International: Arlington, VA, USA, 2005.

19. Badewa, E.; Unc, A.; Cheema, M.; Kavanagh, V.; Galagedara, L. Soil moisture mapping using multi-frequency and multi-coil electromagnetic induction sensors on managed Podzols. Agronomy 2018, 8, 224. [CrossRef] 
20. Wessels, K.J.; Prince, S.D.; Malherbe, J.; Small, J.; Frost, P.E.; Vanzyl, D. Can human-induced land degradation be distinguished from the effects of rainfall variability? J. Arid. Environ. 2007, 68, 271-297.

21. Luo, Q. Temperature thresholds and crop production: A review. Clim. Chang. 2011, 109, 583-598. [CrossRef]

22. Zhao, F.; Xu, B.; Yang, X.; Jin, Y.; Li, J.; Xia, L.; Chen, S.; Ma, H. Remote Sensing Estimates of Grassland Aboveground Biomass Based on MODIS Net Primary Productivity (NPP): A Case Study in the Xilingol Grassland of Northern China. Remote Sens. 2014, 6, 5368-5386. [CrossRef]

23. Jin, Y.; Yang, X.; Qiu, J.; Li, J.; Gao, T.; Wu, Q.; Zhao, F.; Ma, H.; Yu, H.; Xu, B. Remote Sensing-Based Biomass Estimation and Its Spatio-Temporal Variations in Temperate Grassland, Northern China. Remote Sens. 2014, 6, 1496-1513. [CrossRef]

24. Gao, T.; Yang, X.C.; Jin, Y.X.; Ma, H.L.; Li, J.Y.; Yu, H.D.; Yu, Q.Y.; Xiao, Z.; Xu, B. Spatio-temporal variation in vegetation biomass and its relationships with climate factors in the Xilingol grasslands, Northern China. PLOS ONE 2013, 8, e83824. [CrossRef] [PubMed]

25. Sala, O.E.; Parton, W.J. Primary production of the central grassland region of the United States. Ecology 1988, 69, 40-45. [CrossRef]

26. Maki, M.; Ishiahra, M.; Tamura, M. Estimation of leaf water status to monitor the risk of forest fires by using remotely sensed data. Remote Sens. Environ. 2004, 90, 441-450. [CrossRef]

27. Schmidt, M.; Carter, J.; Stone, G.; O’Reagain, P. Integration of optical and X-band radar data for pasture biomass estimation in an open savannah woodland. Remote Sens. 2016, 8, 989. [CrossRef]

28. Lumbierres, M.; Méndez, P.F.; Bustamante, J.; Soriguer, R.; Santamaria, L. Modeling biomass production in seasonal wetlands using Modis NDVI land surface phenology. Remote Sens. 2017, 9, 392. [CrossRef]

29. Trotter, M.G.; Lamb, D.W.; Donald, G.E.; Schneider, D.A. Evaluating an active optical sensor for quantifying and mapping green herbage mass and growth in a perennial grass pasture. Crop Pasture Sci. 2010, 61, 389-398. [CrossRef]

30. Schaefer, M.T.; Lamb, D.W. A combination of plant NDVI and Lidar measurements improve the estimation of pasture biomass in Tall Fescue (Festuca Arundinacea Var. Fletcher). Remote Sens. 2016, 8, 109. [CrossRef]

31. Edirisinghe, A.; Clark, D.; Waugh, D. Spatio-temporal modelling of biomass of intensively grazed perennial dairy pastures using multispectral remote sensing. Int. J. Appl. Earth Obs. 2012, 16, 5-16. [CrossRef]

(C) 2019 by the authors. Licensee MDPI, Basel, Switzerland. This article is an open access article distributed under the terms and conditions of the Creative Commons Attribution (CC BY) license (http://creativecommons.org/licenses/by/4.0/). 